\title{
B-Type Natriuretic Peptide in the Critically Ill with Acute Kidney Injury
}

\author{
Massimo de Cal, ${ }^{1,2}$ Mikko Haapio, ${ }^{1,3}$ Dinna N. Cruz, ${ }^{1}$ Paolo Lentini,, ${ }^{1,2}$ Andrew A. House, ${ }^{1,4}$ \\ Ilona Bobek, ${ }^{1}$ Grazia M. Virzì, ${ }^{1}$ Valentina Corradi, ${ }^{1}$ Flavio Basso, ${ }^{1}$ Pasquale Piccinni, ${ }^{5}$ \\ Angela D'Angelo, ${ }^{2}$ Jamie W. Chang, ${ }^{6}$ Mitchell H. Rosner, ${ }^{6}$ and Claudio Ronco ${ }^{1}$
}

\author{
${ }^{1}$ Department of Nephrology, San Bortolo Hospital, 36100 Vicenza, Italy \\ ${ }^{2}$ Division of Nephrology, University of Padua, 35122 Padua, Italy \\ ${ }^{3}$ Division of Nephrology, Meilahti Hospital, HUCH, 00029 Helsinki, Finland \\ ${ }^{4}$ Division of Nephrology, London Health Sciences Center, London ON, Canada N6A 5A5 \\ ${ }^{5}$ Intensive Care Unit, San Bortolo Hospital, 36100 Vicenza, Italy \\ ${ }^{6}$ Division of Nephrology, University of Virginia Health System, Charlottesville, VA 22908, USA
}

Correspondence should be addressed to Dinna N. Cruz, dinnacruzmd@yahoo.com

Received 20 July 2010; Revised 12 January 2011; Accepted 25 April 2011

Academic Editor: Anjay Rastogi

Copyright (C) 2011 Massimo de Cal et al. This is an open access article distributed under the Creative Commons Attribution License, which permits unrestricted use, distribution, and reproduction in any medium, provided the original work is properly cited.

\begin{abstract}
Introduction. Acute kidney injury (AKI) is common in the intensive care unit (ICU) and associated with poor outcome. Plasma B-type natriuretic peptide (BNP) is a biomarker related to myocardial overload, and is elevated in some ICU patients. There is a high prevalence of both cardiac and renal dysfunction in ICU patients. Aims. To investigate whether plasma BNP levels in the first 48 hours were associated with AKI in ICU patients. Methods. We studied a cohort of 34 consecutive ICU patients. Primary outcome was presence of AKI on presentation, or during ICU stay. Results. For patients with AKI on presentation, BNP was statistically higher at 24 and 48 hours than No-AKI patients ( 865 versus $148 \mathrm{pg} / \mathrm{mL} ; 1380$ versus $131 \mathrm{pg} / \mathrm{mL}$ ). For patients developing AKI during 48 hours, BNP was statistically higher at 0, 24 and 48 hours than No-AKI patients (510 versus $197 \mathrm{pg} / \mathrm{mL} ; 552$ versus $124 \mathrm{pg} / \mathrm{mL} ; 949$ versus $104 \mathrm{pg} / \mathrm{mL}$ ). Conclusion. Critically ill patients with AKI on presentation or during ICU stay have higher levels of the cardiac biomarker BNP relative to No-AKI patients. Elevated levels of plasma BNP may help identify patients with elevated risk of AKI in the ICU setting. The mechanism for this cardiorenal connection requires further investigation.
\end{abstract}

\section{Introduction}

Acute kidney injury (AKI) is a common clinical problem in intensive care unit (ICU) patients and independently predicts poor outcome [1-4]. In the ICU setting, the overall incidence of AKI is approximately $36 \%[5,6]$, and an increasing trend has been reported $[7,8]$. Cardiac dysfunction is also common in patients with AKI in the ICU, and increasing interest exists in how the interaction of these two systems affects clinical outcomes in this group of patients.

B-type or brain natriuretic peptide (BNP) is a neurohormone secreted from ventricular myocardium in response to myocardial stretching and volume overload [9]. BNP has diagnostic and prognostic utility in patients with acute decompensated heart failure [10-13], and BNP is an independent predictor for cardiovascular events and overall mortality in various patient groups including those with chronic kidney disease [14-20].

However, it remains unclear whether plasma levels of BNP are useful in predicting AKI in critically ill patients. Therefore, our study aimed to investigate whether BNP levels in the first 48 hours may be useful in diagnosis of established AKI.

\section{Methods}

2.1. Patients and Study Protocol. We studied a cohort of 34 consecutive patients admitted to the ICU of "San Bortolo" Hospital, Vicenza, Italy, between December 2007 and April 
2008. Patients requiring mechanical ventilation and admitted on any day from Monday to Wednesday were included, and we excluded patients with acute coronary syndrome or acute myocardial infarction. The study was approved by the Institutional Review Board. The primary outcome was presence of AKI during admission or development of AKI during ICU stay. Patients were classified as having AKI if any time during the first 48 hours after enrollment they had

(1) an increment of serum creatinine ( $\mathrm{SCr}$ ) of $0.3 \mathrm{mg} / \mathrm{dL}$ or more or an increase of at least $50 \%$ from baseline and/or,

(2) an episode of urine output less than $0.5 \mathrm{~mL} / \mathrm{kg} / \mathrm{hr}$ for more than six hours despite fluid challenge of $500 \mathrm{~mL}$ or more.

AKI was classified according to the RIFLE (Risk, Injury, Failure, Loss, and End-stage kidney disease) criteria [21]. The Sequential Organ Failure Assessment (SOFA) scores were calculated using standard methods [22]. Blood samples for plasma BNP and renal function were taken within 6 hours from admission and 24 and 48 hours later, to investigate association of BNP levels with clinical and laboratory parameters and SOFA score.

2.2. BNP Measurement. Plasma samples for BNP were stored at minus 80 degrees Celsius. Plasma BNP was measured with fluorescence-based immunoassay with the Triage point-ofcare analyzer (Biosite Inc., San Diego, Calif., USA), which is a rapid quantitative measurement of BNP concentration in EDTA-anticoagulated whole blood or plasma. The method used single-use plastic cartridge with immobilized BNP antigen and BNP-specific monoclonal antibodies conjugated to fluorescent nanoparticles.

2.3. Statistical Analysis. Categorical variables are expressed as percentage and were compared with Fisher's Exact Test. Normally or near normally distributed variables were presented as means \pm standard deviations (SD); non-normally distributed continuous data were presented as medians and interquartile ranges (IQR). Differences between groups were analyzed using Student's $t$ and Mann-Whitney tests as appropriate. Differences between repeated measures within a group were analyzed using Friedman test. Statistical analysis was performed using the SPSS 15.0 (SPSS Inc, Chicago, Ill, USA). A $P$ value $<.05$ was considered significant.

\section{Results}

During the study, a total of 34 patients were admitted to the ICU, and, of these, 26 met the inclusion criteria and had sufficient data for analysis. Furthermore, 9 (34.6\%) fulfilled criteria for AKI, 5 (19.2\%) had AKI on admission, and $4(15.4 \%)$ more developed AKI during 48 hours. Characteristics of the patients are shown in Tables 1 and 2 . Given the differences between SCr, age, and BNP at baseline, we did examine for correlations between these variables. While baseline SCr and BNP were not significantly correlated ( $r=0.27, P=.19)$, there was a weak correlation between

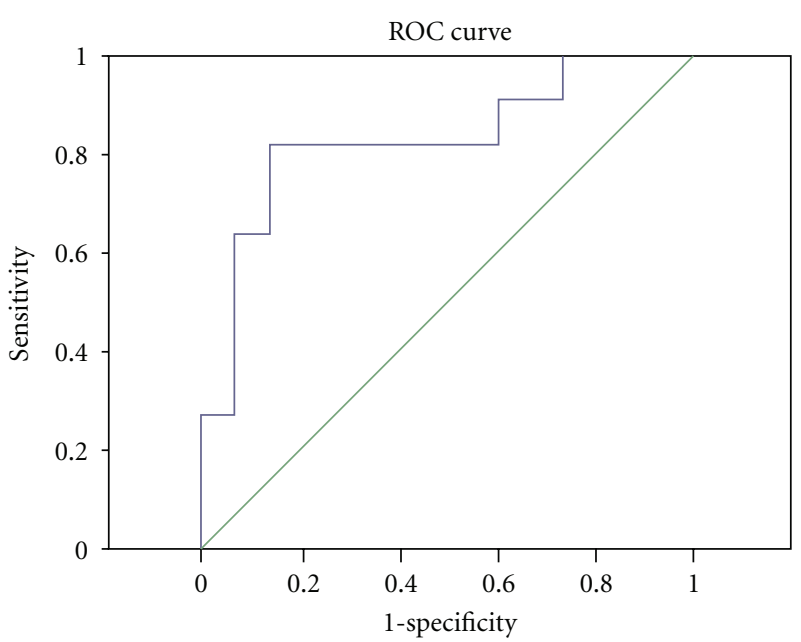

ROC receiver operating characteristic AUC area under the curve BNPB-type or brain natriuretic peptide AKI acute kidney injury ICU intensive care unit

FIGURE 1: The ROC-AUC for BNP related to the presence of AKI on admission or development of AKI during ICU stay is 0.830 .

age and $\mathrm{SCr}(r=0.39, P=.048)$ and a stronger correlation between age and baseline $\operatorname{BNP}(r=.46, P=.02)$.

In patients with AKI on admission, we found a higher SOFA score $(10.0 \pm 2.4$ versus $6.1 \pm 2.1 ; P=.002)$ and, as expected, higher SCr levels (1.85, IQR 1.76-1.94, versus 0.82 , IQR $0.69-1.00 \mathrm{mg} / \mathrm{dL} ; P=.001)$ compared to noAKI patients. Moreover, AKI patients tended to have higher BNP values on admission compared to no-AKI patients (510, IQR 370-544, versus 197, IQR 57-393 pg/mL; $P=$ .06) (Table 1). Plasma BNP levels were also statistically significantly higher for AKI patients at 24 and 48 hours after admission compared to no-AKI patients (Table 3 ). In addition, the increase in BNP of AKI patients during 48 hours (from 510 to $1380 \mathrm{pg} / \mathrm{mL}$ ) was significant $(P=.012)$ (Table 3 and Figure 2).

An additional 4 patients developed AKI after admission. These patients had on admission higher SCr (1.14 versus $0.82 \mathrm{mg} / \mathrm{dL}$ ) and BNP (338 versus $197 \mathrm{pg} / \mathrm{mL}$ ) levels compared to no-AKI patients.

We also analyzed levels of SCr and BNP in all patients developing AKI at any point during 48 hours $(n=9)$. For these patients, the difference in BNP versus no-AKI patients at admission was even more pronounced (510, IQR 232832 , versus $197, \mathrm{IQR} 36-353 \mathrm{pg} / \mathrm{mL} ; P=.038)$. Also, for the 9 patients developing AKI at any time during ICU stay, SCr and BNP levels at baseline and at 24 and 48 hours were significantly higher compared to no-AKI patients (Table 4).

\section{Discussion}

A large proportion of patients admitted to hospital, especially in the critical care setting, have various degrees of heart and kidney dysfunction [23]. Primary disorders of one of 
TABLE 1: Characteristics of AKI and no-AKI patients at ICU admission.

\begin{tabular}{|c|c|c|c|c|}
\hline & $\begin{array}{l}\text { All } \\
(26)\end{array}$ & $\begin{array}{l}\text { AKI } \\
(5)\end{array}$ & $\begin{array}{c}\text { No-AKI } \\
(21)\end{array}$ & $P$ value \\
\hline Male & $57.7 \%$ & $60.0 \%$ & $57.1 \%$ & .91 \\
\hline Age, years & $59.7 \pm 21.7$ & $77.6 \pm 7.3$ & $55.4 \pm 21.9$ & .037 \\
\hline Weight, kg & $77.4 \pm 13.4$ & $74.5 \pm 8.8$ & $78.1 \pm 14.3$ & .36 \\
\hline SOFA score & $6.9 \pm 2.7$ & $10.0 \pm 2.4$ & $6.1 \pm 2.1$ & .002 \\
\hline $\begin{array}{l}\text { Serum creatinine, } \\
\mathrm{mg} / \mathrm{dL}^{*}\end{array}$ & $\begin{array}{c}0.89 \\
\text { (0.64 to } 1.28)\end{array}$ & $\begin{array}{c}1.85 \\
(1.76 \text { to } 1.94)\end{array}$ & $\begin{array}{c}0.82 \\
\text { (0.69 to } 1.00)\end{array}$ & .001 \\
\hline $\begin{array}{l}\text { Plasma BNP, } \\
\mathrm{pg} / \mathrm{mL}^{*}\end{array}$ & $\begin{array}{c}228 \\
\text { (67.5 to } 544)\end{array}$ & $\begin{array}{c}510 \\
\text { (370 to } 544)\end{array}$ & $\begin{array}{c}197 \\
\text { (57 to } 393 \text { ) }\end{array}$ & .06 \\
\hline \multicolumn{5}{|l|}{$\begin{array}{l}\text { Diagnosis on ICU } \\
\text { admission }\end{array}$} \\
\hline Trauma & $30.8 \%$ & $0 \%$ & $38.1 \%$ & .28 \\
\hline Pulmonary & $26.9 \%$ & $60 \%$ & $19.0 \%$ & .10 \\
\hline Neurologic & $26.9 \%$ & $0 \%$ & $33.3 \%$ & .28 \\
\hline Other & $15.4 \%$ & $40.0 \%$ & $9.5 \%$ & .16 \\
\hline
\end{tabular}

AKI: Acute kidney injury.

ICU: Intensive care unit.

SOFA: Sequential organ failure assessment.

BNP: B-type or brain natriuretic peptide.

*median and interquartile range.

TABLE 2: Median of creatinine and BNP of all patients during 48 hours.

\begin{tabular}{lcccc}
\hline & Baseline & 24 hours & 48 hours & \\
\hline Serum creatinine, mg/dL & 0.89 & 0.86 & 0.80 & $(0.71$ to 0.89$)$ \\
& $(0.64$ to 1.28$)$ & $(0.65$ to 1.50$)$ & 220 & .86 \\
Plasma BNP, pg/mL & 228 & 282.5 & $(78.4$ to 565$)$ & .92 \\
\hline
\end{tabular}

BNP: B-type or brain natriuretic peptide.

TABLE 3: Median of creatinine and BNP during 48 hours of ICU stay for patients with or without AKI on admission to ICU. The increase in BNP of AKI patients is significant $(P=.012)$.

\begin{tabular}{|c|c|c|c|c|}
\hline & & $\begin{array}{c}\text { AKI } \\
(5)\end{array}$ & $\begin{array}{c}\text { No-AKI } \\
(21)\end{array}$ & $P$ value \\
\hline \multirow{3}{*}{ Serum creatinine, $\mathrm{mg} / \mathrm{dL}$} & Baseline & $\begin{array}{c}1.85 \\
(1.70 \text { to } 3.85)\end{array}$ & $\begin{array}{c}0.82 \\
(0.68 \text { to } 1.01)\end{array}$ & .001 \\
\hline & 24 hours & $\begin{array}{c}2.49 \\
(1.60 \text { to } 4.53)\end{array}$ & $\begin{array}{c}0.79 \\
(0.64 \text { to } 0.97)\end{array}$ & .001 \\
\hline & 48 hours & $\begin{array}{c}2.14 \\
(1.47 \text { to } 5.24) \\
\end{array}$ & $\begin{array}{c}0.78 \\
(0.63 \text { to } 0.89) \\
\end{array}$ & .004 \\
\hline \multirow{3}{*}{ Plasma BNP, pg/mL } & Baseline & $\begin{array}{c}510 \\
(369 \text { to } 690)\end{array}$ & $\begin{array}{c}197 \\
(42 \text { to } 485)\end{array}$ & .06 \\
\hline & 24 hours & $\begin{array}{c}865 \\
\text { (344 to } 948)\end{array}$ & $\begin{array}{c}148 \\
\text { (47 to } 447)\end{array}$ & .047 \\
\hline & 48 hours & $\begin{array}{c}1380 \\
\text { (985 to } 1625)\end{array}$ & $\begin{array}{c}131 \\
\text { (43 to } 297 \text { ) }\end{array}$ & $<.001$ \\
\hline
\end{tabular}

BNP: B-type or brain natriuretic peptide.

ICU: Intensive care unit.

AKI: Acute kidney injury. 
TABLE 4: Median of creatinine and BNP during 48 hours for patients developing AKI or not any time during their ICU stay.

\begin{tabular}{|c|c|c|c|c|}
\hline & & $\begin{array}{l}\text { AKI } \\
(9)\end{array}$ & $\begin{array}{l}\text { No-AKI } \\
(17)\end{array}$ & $P$ value \\
\hline \multirow{3}{*}{ Serum creatinine, $\mathrm{mg} / \mathrm{dL}$} & Baseline & $\begin{array}{c}1.76 \\
(1.01 \text { to } 1.90)\end{array}$ & $\begin{array}{c}0.81 \\
(0.68 \text { to } 0.89)\end{array}$ & .002 \\
\hline & 24 hours & $\begin{array}{c}1.70 \\
(1.07 \text { to } 2.53)\end{array}$ & $\begin{array}{c}0.70 \\
(0.63 \text { to } 0.89)\end{array}$ & .001 \\
\hline & 48 hours & $\begin{array}{c}1.56 \\
(0.98 \text { to } 2.47) \\
\end{array}$ & $\begin{array}{c}0.74 \\
(0.62 \text { to } 0.82) \\
\end{array}$ & .001 \\
\hline \multirow{3}{*}{ Plasma BNP, pg/mL } & Baseline & $\begin{array}{c}510 \\
(232 \text { to } 832)\end{array}$ & $\begin{array}{c}197 \\
\text { (36 to } 353)\end{array}$ & .038 \\
\hline & 24 hours & $\begin{array}{c}552 \\
\text { (344 to } 948)\end{array}$ & $\begin{array}{c}124 \\
\text { (47 to } 407)\end{array}$ & .019 \\
\hline & 48 hours & $\begin{array}{c}949 \\
\text { (297 to } 1435)\end{array}$ & $\begin{array}{c}104 \\
\text { (29 to } 236)\end{array}$ & .002 \\
\hline
\end{tabular}

BNP: B-type or brain natriuretic peptide.

AKI: Acute kidney injury.

ICU: Intensive care unit.

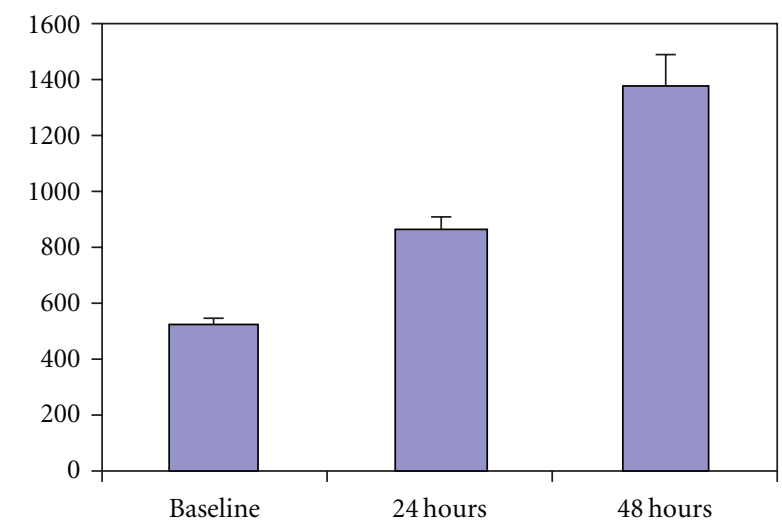

$\mathrm{BNP}(\mathrm{pg} / \mathrm{mL})$

BNPB-type or brain natriuretic peptide AKI acute kidney injury ICU intensive care unit

FIgure 2: Increase in median of BNP of patients with AKI on admission to ICU $(P=.012)$.

these two organs often result in secondary dysfunction or injury to the other [24]. Such pathophysiological interactions represent the basis for a clinical entity often referred to as the cardiorenal syndrome (CRS) [25]. Limited data are available regarding the diagnostic and prognostic utility of $\mathrm{BNP}$ in patients with AKI in intensive care unit. In a recent study, Park et al. [26] demonstrated that BNP levels have the diagnostic and prognostic capability for CRS type 4 in ICU patients, according to the novel classification of CRS $[27,28]$. In our study, BNP was able to predict the presence of AKI on admission or development of AKI during ICU stay with a ROC-AUC 0.830 (Figure 1). No previous studies have focused on the significance of BNP in patients with AKI admitted to the ICU.
In ICU setting, emerging cardiac and renal impairment are strongly connected on neurohormonal basis via reninangiotensin-aldosterone system BNP and nitric oxide, the sympathetic nervous system and other pathways such as coagulation and inflammation.

Burchill et al. have shown in experimental animal models that the acute effects of AKI on the heart occur as early as few hours after kidney injury, and that changes in cardiac structure are associated with increased cardiac BNP [29].

It could also be speculated that the changes in BNP observed in our study may partly reflect the pathophysiology between kidney and heart in AKI, the so-called CRS type 3 or acute renocardiac syndrome. In this category, AKI is believed to be the primary inciting factor, and cardiac failure is a common and in often times a fatal complication of AKI [27].

In our study, we demonstrate a dynamic interaction between AKI and plasma BNP levels in a cohort of mechanically ventilated ICU patients who were admitted primarily for noncardiac diagnosis. This calls attention to the possible utility of this marker in detecting AKI. Further, the results support the need for additional study of the potential value of plasma BNP levels in discrimination between AKI and noAKI in critically ill patients.

To our knowledge, this is the first investigation of the association between plasma BNP levels and AKI in critically ill patients. We acknowledge some limitations in this study. Extensive information regarding patient comorbidities was not available and could not be added to our analysis. Plasma BNP levels can be affected by other variables such as age, and in our study AKI patients were significantly older than no-AKI patients, and age was correlated with baseline BNP, hence some of the association between BNP and AKI may have reflected the risk of AKI related to age. Additionally, while patients with acute myocardial infarction and acute coronary syndromes were excluded, massive information about previous or current cardiac dysfunction was not collected and could have influenced plasma BNP levels. 
Furthermore, we did not perform objective assessment of cardiac function to document that increased BNP in this setting would be due to myocardial dysfunction. Finally, this study was not designed to look at the prognostic value of plasma BNP levels in critically ill patients with AKI. We hope that these preliminary results will encourage further study of these important questions.

\section{Conclusion}

In this pilot study, we have demonstrated for the first time an association between plasma BNP levels and AKI in critically ill patients. Patients with AKI have higher levels of BNP compared to no-AKI patients, and in AKI patients BNP levels continue to increase during the subsequent 48 hours. Our results suggest that plasma BNP may distinguish the occurrence of AKI. Additional studies are necessary to confirm our findings and to further shed light on the pathophysiologic interaction between kidney and heart during AKI.

\section{Acknowledgment}

The authors are grateful for the assistance of staff in Hospital Intensive Care Unit, San Bortolo in carrying out this study.

\section{References}

[1] S. M. Bagshaw, K. B. Laupland, C. J. Doig et al., "Prognosis for long-term survival and renal recovery in critically ill patients with severe acute renal failure: a population-based study," Critical Care, vol. 9, no. 6, pp. R700-R709, 2005.

[2] M. Korkeila, E. Ruokonen, and J. Takala, "Costs of care, long-term prognosis and quality of life in patients requiring renal replacement therapy durino intensive care," Journal of Intensive Care Medicine, vol. 26, no. 12, pp. 1824-1831, 2000.

[3] P. G. Metnitz, C. G. Krenn, H. Steltzer et al., "Effect of acute renal failure requiring renal replacement therapy on outcome in critically ill patients," Critical Care Medicine, vol. 30, no. 9, pp. 2051-2058, 2002.

[4] S. Uchino, J. A. Kellum, R. Bellomo et al., "Acute renal failure in critically ill patients: a multinational, multicenter study," Journal of the American Medical Association, vol. 294, no. 7, pp. 813-818, 2005.

[5] S. M. Bagshaw, C. George, I. Dinu, and R. Bellomo, "A multi-centre evaluation of the RIFLE criteria for early acute kidney injury in critically ill patients," Nephrology Dialysis Transplantation, vol. 23, no. 4, pp. 1203-1210, 2008.

[6] M. Ostermann and R. W. Chang, "Acute kidney injury in the intensive care unit according to RIFLE," Critical Care Medicine, vol. 35, no. 8, pp. 1837-1843, 2007.

[7] S. M. Bagshaw, C. George, and R. Bellomo, "Changes in the incidence and outcome for early acute kidney injury in a cohort of Australian intensive care units," Critical Care, vol. 11, Article ID R68, 2007.

[8] J. L. Xue, F. Daniels, R. A. Star et al., "Incidence and mortality of acute renal failure in Medicare beneficiaries, 1992 to 2001," Journal of the American Society of Nephrology, vol. 17, no. 4, pp. 1135-1142, 2006.

[9] H. M. Azzazy and R. H. Christenson, "B-type natriuretic peptide: physiologic role and assay characteristics," Heart Failure Reviews, vol. 8, no. 4, pp. 315-320, 2003.
[10] I. S. Anand, L. D. Fisher, Y. T. Chiang et al., "Changes in brain natriuretic peptide and norepinephrine over time and mortality and morbidity in the Valsartan Heart Failure Trial (Val-HeFT)," Circulation, vol. 107, no. 9, pp. 1278-1283, 2003.

[11] A. S. Maisel, P. Krishnaswamy, R. M. Nowak et al., "Rapid measurement of B-type natriuretic peptide in the emergency diagnosis of heart failure," The New England Journal of Medicine, vol. 347, no. 3, pp. 161-167, 2002.

[12] C. Mueller, A. Scholer, K. Laule-Kilian et al., "Use of B-type natriuretic peptide in the evaluation and management of acute dyspnea," The New England Journal of Medicine, vol. 350, no. 7, pp. 647-654, 2004.

[13] S. J. Wieczorek, A. H. B. Wu, R. Christenson et al., "A rapid Btype natriuretic peptide assay accurately diagnoses left ventricular dysfunction and heart failure: a multicenter evaluation," American Heart Journal, vol. 144, no. 5, pp. 834-839, 2002.

[14] W. J. Austin, V. Bhalla, I. Hernandez-Arce et al., "Correlation and prognostic utility of B-type natriuretic peptide and its amino-terminal fragment in patients with chronic kidney disease," American Journal of Clinical Pathology, vol. 126, no. 4, pp. 506-512, 2006.

[15] P. A. McCullough, P. Duc, T. Omland et al., "B-type natriuretic peptide and renal function in the diagnosis of heart failure: an analysis from the Breathing Not Properly Multinational Study," American Journal of Kidney Diseases, vol. 41, no. 3, pp. 571-579, 2003.

[16] B. Meyer, M. Huelsmann, P. Wexberg et al., "N-terminal pro-B-type natriuretic peptide is an independent predictor of outcome in an unselected cohort of critically ill patients," Critical Care Medicine, vol. 35, no. 10, pp. 2268-2273, 2007.

[17] R. Latini, S. Masson, I. Anand et al., "The comparative prognostic value of plasma neurohormones at baseline in patients with heart failure enrolled in Val-HeFT," European Heart Journal, vol. 25, no. 4, pp. 292-299, 2004.

[18] S. J. Carr, S. Bavanandan, B. Fentum, and L. Ng, "Prognostic potential of brain natriuretic peptide (BNP) in predialysis chronic kidney disease patients," Clinical Science, vol. 109, no. 1, pp. 75-82, 2005.

[19] W. J. Austin, V. Bhalla, I. Hernandez-Arce et al., "Correlation and prognostic utility of B-type natriuretic peptide and its amino-terminal fragment in patients with chronic kidney disease," American Journal of Clinical Pathology, vol. 126, no. 4, pp. 506-512, 2006.

[20] M. Suresh and K. Farrington, "Natriuretic peptides and the dialysis patient," Seminars in Dialysis, vol. 18, no. 5, pp. 409419, 2005.

[21] R. Bellomo, C. Ronco, J. A. Kellum, R. L. Mehta, and P. Palevsky, "Acute renal failure-definition, outcome measures, animal models, fluid therapy and information technology needs: the second international consensus conference of the Acute Dialysis Quality Initiative (ADQI) Group," Critical Care (London, England), vol. 8, no. 4, pp. R204-R212, 2004.

[22] J. L. Vincent, A. de Mendonça, F. Cantraine et al., "Use of the SOFA score to assess the incidence of organ dysfunction/failure in intensive care units: results of a multicenter, prospective study," Critical Care Medicine, vol. 26, no. 11, pp. 1793-1800, 1998.

[23] O. Dar and M. R. Cowie, "Acute heart failure in the intensive care unit: epidemiology," Critical Care Medicine, vol. 36, no. 1, pp. S3-S8, 2008.

[24] R. W. Schrier, "Cardiorenal versus renocardiac syndrome: is there a difference?" Nature Clinical Practice Nephrology, vol. 3 , no. 12 , p. 637, 2007. 
[25] C. Ronco, "Cardiorenal and renocardiac syndromes: clinical disorders in search of a systematic definition," International Journal of Artificial Organs, vol. 31, no. 1, pp. 1-2, 2008.

[26] S. Park, G. Y. Cho, S. G. Kim et al., "Brain natriuretic peptide levels have diagnostic and prognostic capability for cardiorenal syndrome type 4 in intensive care unit patients," Critical Care, vol. 13, no. 3, Article ID R70, 2009.

[27] C. Ronco, M. Haapio, A. A. House, N. Anavekar, and R. Bellomo, "Cardiorenal syndrome," Journal of the American College of Cardiology, vol. 52, no. 19, pp. 1527-1539, 2008.

[28] T. Breidthardt, A. Mebazaa, and C. E. Mueller, "Predicting progression in nondiabetic kidney disease: the importance of cardiorenal interactions," Kidney International, vol. 75, no. 3, pp. 253-255, 2009.

[29] L. Burchill, E. Velkoska, R. G. Dean et al., "Acute kidney injury in the rat causes cardiac remodelling and increases angiotensin-converting enzyme 2 expression," Experimental Physiology, vol. 93, no. 5, pp. 622-630, 2008. 


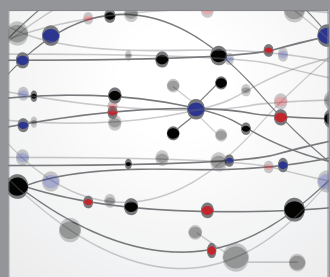

The Scientific World Journal
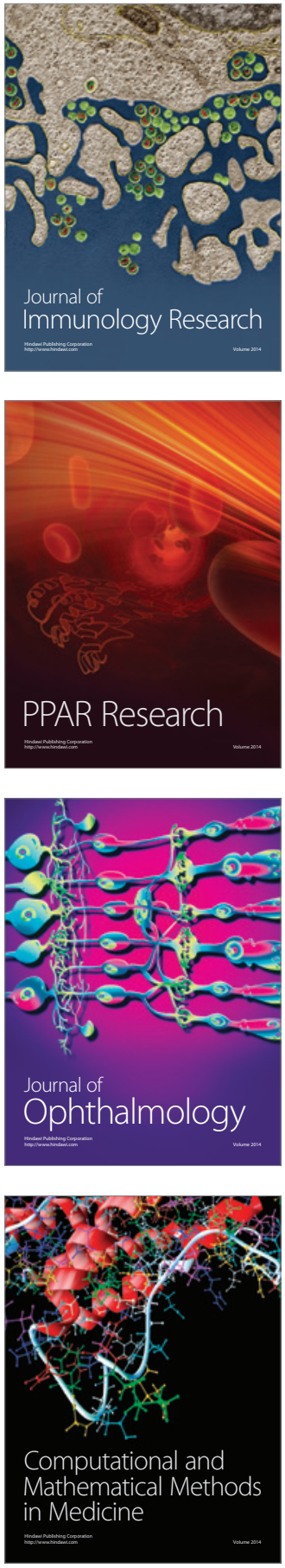



Gastroenterology

Research and Practice
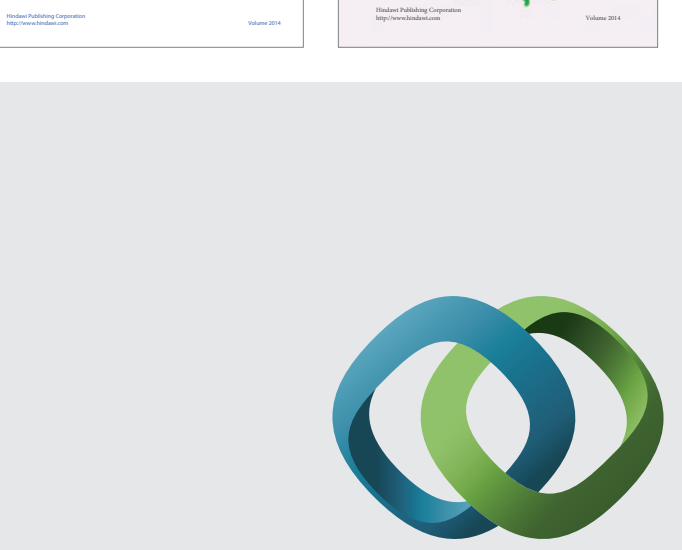

\section{Hindawi}

Submit your manuscripts at

http://www.hindawi.com


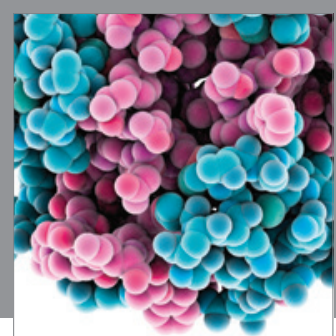

Journal of
Diabetes Research

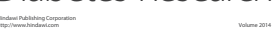

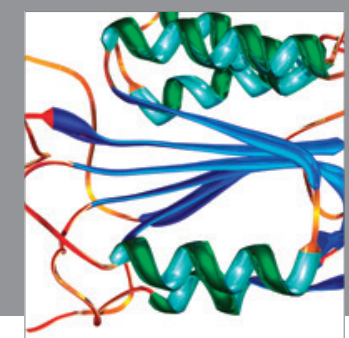

Disease Markers
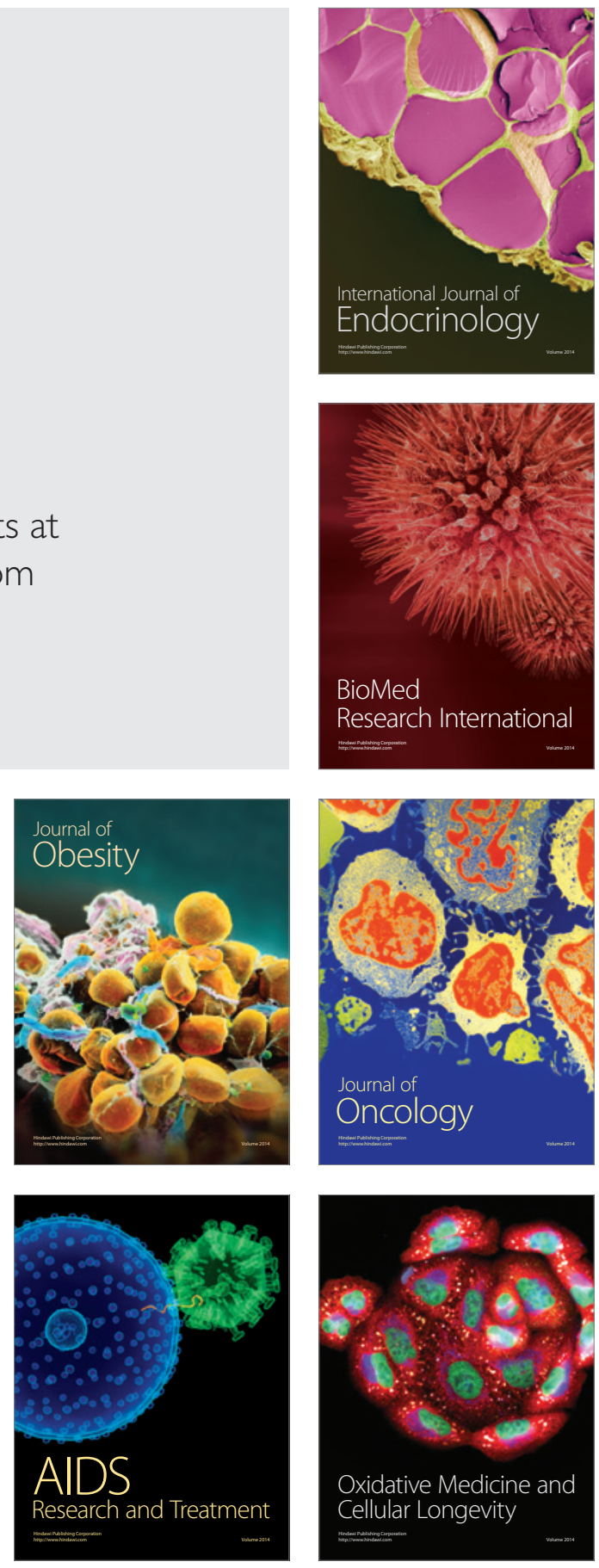